\title{
Obesity, Economic Growth: The COVID-19 Pandemic, and Poverty
}

\author{
Tahereh Alavi Hojjat \\ DeSales University
}

\author{
Juan Daniel Morocho Ruiz \\ National University of Piura
}

\begin{abstract}
Over the past several decades, obesity has grown into a major global epidemic. This dramatic rise in rates is more pronounced in developing countries, as compared to more industrialized societies. In Peru, obesity rates are escalating. In this paper, Granger Causality Test in Panel Data, Dynamic Panel Data Analysis, and Cointegration Analysis in Panel Data from 2008 - 2020 in 24 regions with a sample size of 312 data points - is used. We find that there is a cointegration among obesity, poverty, and economic growth, which ensures a long-run relationship between the variables. In addition, our analysis found that regarding the initiative of government regulation, which introduces technical parameters of processed foods and nonalcoholic beverages and which was approved in terms of sugar, sodium and saturated fat content, is not effective. Finally, the results obtained show that the quarantine period in the context of the COVID-19 pandemic also has contributed to an increase in obesity rates in the regions of Peru during the 2008-2020 period.
\end{abstract}

Keywords: obesity, economic growth, Covid-19, cointegration, poverty, health, panel data analysis

\section{INTRODUCTION}

In recent years, obesity has been viewed as the main cause of the most critical health problems that threaten people's health at mass scale. Obesity is defined as excessive fat accumulation and accompanying body mass index (BMI) exceeding $30 \mathrm{~kg} / \mathrm{m} 2$. The worldwide prevalence of obesity has nearly tripled between 1975 and 2016. In 2016, more than 1.9 billion adults, 18 years older, were overweight globally. Of these, over 650 million were obese (The World Health Organization, 2021). In 2019, an estimated 38.2 million children under the age of 5 years were overweight or obese. While just under $1 \%$ of children and adolescents aged 5-19 were obese in 1975, more 124 million children and adolescents (6\% of girls and $8 \%$ of boys) were obese in 2016 (The World Health Organization, 2021). It is assumed that approximately 3.3 billion adults $(57.8 \%)$ will become overweight or obese by 2030 , if the current trend is maintained (Kelly et al., 2008).

Overweight and obesity are linked to more deaths worldwide than underweight. Globally, there are more people who are obese than underweight - this occurs in every region on the planet except parts of sub-Saharan Africa and Asia. Once considered a high-income nation problem, overweight and obesity are now on the rise in low- and middle-income countries, particularly in urban environments. 


\section{FIGURE 1 CAUSES OF OBESITY}

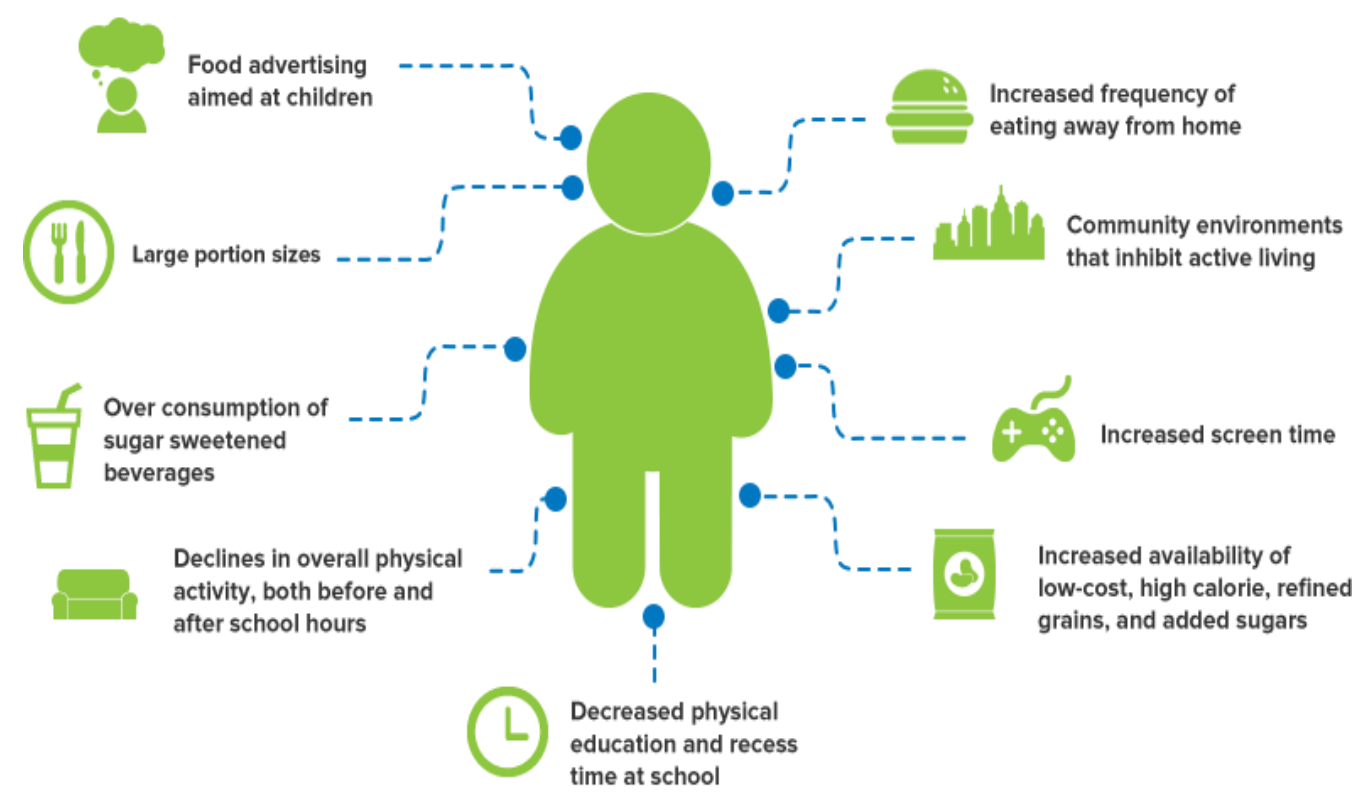

Note. From "Childhood Obesity Causes". Friedman School of Nutrition Science and Technology, Tufts University. (n.d.). ChildObesity180. Retrieved August 1, 2021, from https://childobesity180.org/

Causes of obesity have been studied in numerous research papers, and can be assessed as shifts in lifestyle resulting from complex social evolution. It can result from excess calorie intake, which in turn is due to overconsumption of more readily available calorie-dense food, lack of access to high-quality food, and/or insufficient physical activity and exercise (Monteiro et al., 2004). This is likely due to various other factors, including the spread of the "Western" lifestyle of industrialized countries, which is again associated with readily available food with high sugar and fat content, a more sedentary lifestyle with less activity and exercise, increases in the price of high-quality organic food, and many other factors.

For children in particular, obesity is a serious health concern as obese children and adolescents are likely to become obese as adults. In 2000, approximately $10 \%$ of children ages 5 to 17 years worldwide were overweight and in 2008, 40 million preschool children were overweight (Ahmad, et al. 2010). According to the World Health Organization (WHO, 2020), 38 million children under the age of 5 were overweight and obesity is now on the rise in low-and middle-income countries as well, particularly in urban settings.

The increase in childhood obesity over the past several decades, together with the associated health problems and costs, is raising grave concern among health care professionals, policy experts, child advocates, and parents (Anderson \& Butcher, 2006). At present, obesity is not only problematic from a clinical point of view, but it is also a social issue of grave importance. In addition to physical ailments, obesity has been empirically linked to lower satisfaction with work, strained family relations and partner relationships, lowered social activities, and even depression (Stutzer, 2007).

Latin America is facing a pandemic of malnutrition. Hunger and obesity are rising side by side in the region. The working poor who can't afford a nutritious diet are suffering from periodic food deprivation at times, and at other times, an overabundance of poor-quality food. A new report from a consortium of United Nations (UN) agencies found that the number of people experiencing hunger in Latin America has grown steadily over the last five years (Beaubien, 2020). The report analyzes data through the end of 2019, prior to the arrival of COVID-19. However, the social and economic inequality that were leading to malnutrition in the region have only been exacerbated during the pandemic (Beaubien, 2020). 


\section{Review of Literature on Obesity}

Over the past several decades, obesity has become a truly global epidemic, affecting all age groups, populations, and countries of all income levels (Kelly et al., 2008). The updated report by the Organization for Economic Co-operation and Development (OECD) in 2017 shows that the top two countries with the highest obesity rates are the United States (38.2\%) and Mexico (32.4\%), whereas the countries with the lowest rates are Japan (3.7\%) and South Korea (5.3\%). Equally troubling is that not only is there no clear sign that this epidemic is abating, there is also evidence to suggest that most 2-year-olds today will develop obesity by age 35 (Ludwig \& Rogoff, 2018).

In less developed countries (i.e., with a $\$ 2,500 \mathrm{GDP}$ per capita), excess weight is observed to have a direct relationship with higher social class (Monteiro et al., 2004). In a study of obesity in developing countries by Dinsa et al. (2012), it was found that in low-income countries or countries that scored low on the Human Development Index (HDI), the association between socioeconomic status and obesity appeared to be positive for both men and women. In other words, more affluent and/or adults with more education are on average more likely to be obese.

On the other hand, there are several studies supporting a positive relationship between poverty and obesity in developed countries (Hojjat \& Hojjat, 2017; Devaux \& Sassi, 2013). Studies indicate that obesity is more common among people with lower socioeconomic status in high-income countries, and there is a negative correlation between obesity and education (Hojjat \& Hojjat, 2017; Devaux \& Sassi, 2013). However, this relationship may not be causal and may instead reflect other characteristics of socioeconomic position (e.g., educational attainment, occupation, social environment, health knowledge, and health expectations) (Au \& Johnston, 2014). At the same time, there is another study which includes data from 70 countries, supporting the reversal hypothesis that obesity is more prevalent among well-educated individuals in low-income countries, but becomes more prevalent among uneducated individuals in middleto high-income countries (Kinge et al., 2015).

According to the World Health Organization (WHO) health statistics, the prevalence of obesity increased dramatically in most countries from 2002 to 2014 . These obesity rates show a similar trajectory to those observed in the United States, which rose by $9.2 \%$ from 2002 to 2014. Especially striking are consistently higher percentages for obesity among Peruvian women (Hojjat \& Morocho, 2019). It has been proposed that this might be a consequence of the particular culture and lifestyle, where outdoor activity and exercise are uncommon for women (Iseri \& Arslan, 2009).

FIGURE 2

\section{OBESITY IN PERUVIAN WOMEN AGED 15-49 YEARS OLD, 2008-2020}

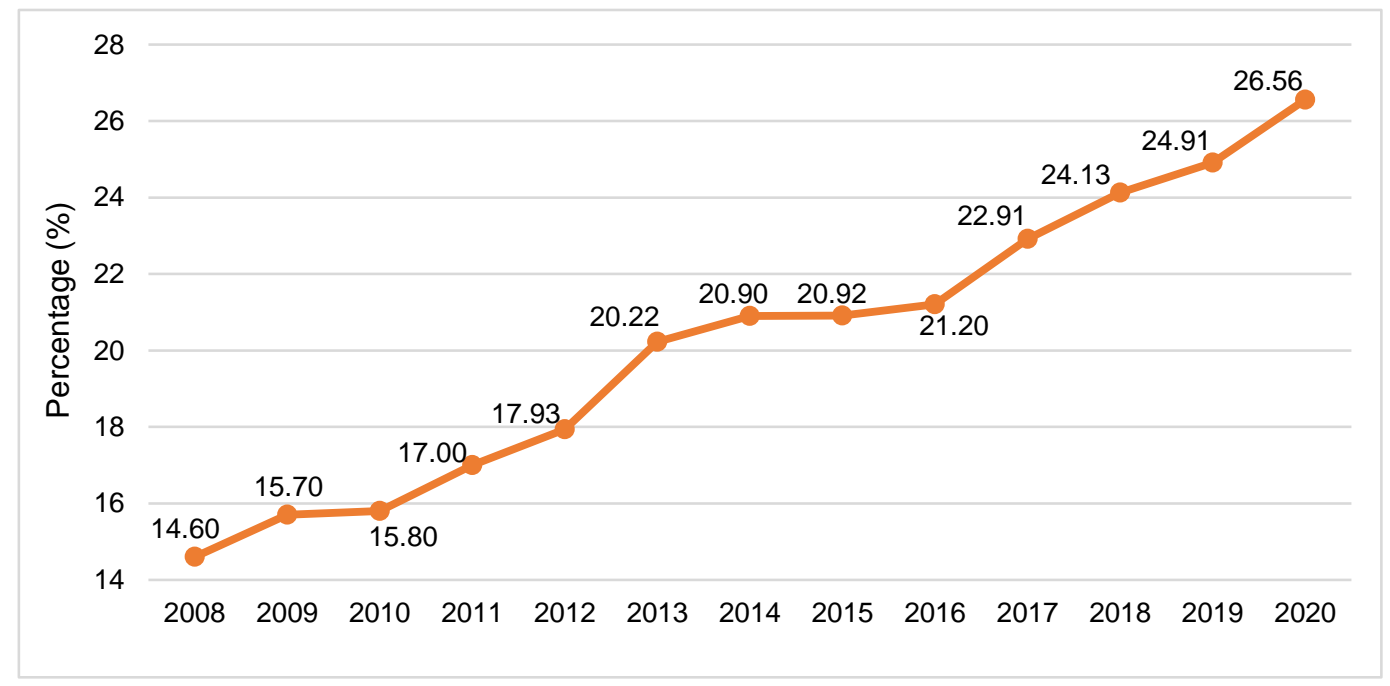

Note. From Family Health and Demographic Survey (ENDES), 2008- 2020. 
Over the past several decades, obesity has become a significant global epidemic. Across the globe, obesity is also related with long term negative consequences. It appears to cause numerous medical complications including sleep apnea, stroke, diabetes, liver disease and various types of cancer (see Figure 3). It also affects school attendance, social interaction, and future earnings.

Weight bias can have a significant impact on social, economic, psychological, and physical health. Social and economic consequences include social rejection, poor quality of relationships, worse academic outcomes and lower socioeconomic status (Friedman \& Puhl, 2012). In poorer societies, both obesity and heart disease are more common among rich; however, as societies become richer, both diseases tend to reverse their social distribution and become more common among the poor. Studies have found that among poorer countries it is more unequal ones which have more underweight people - the opposite of the pattern among the rich countries (Wilkinson \& Pickett, 2009).

John McArthur (July 19, 2019), a senior fellow in the Global Economy and Development program, stated the following in his podcast with Brookings Institution:

In addition to the numbers of hungry rising - there is another worrisome problem, which is the obesity, the over-nutrition or poor nutrition at the other end of the spectrum, which is going up in pretty much every part of the world. And so, we have these twin nutrition challenges happening globally and it's almost paradoxical that 800 million people in extreme problems of undernourishment, and then you have in some places, $20 \%, 30 \%$ and more percent of the population grappling with poor nutrition. And it's often because they're eating a lot of volume, but the quality of their calories is really bad because those are the cheapest calories. And so, that is a real health crisis in the making that we'll be paying for decades to come.

Evidence suggests that multiple influences acting at different scales may be contributing to the rise of obesity. These influences include genetics, biology, individual behaviors, social network dynamics, the environment, and larger societal forces. The biological scale includes physiological processes such as leptin sensitivity and individual metabolism. Individual behaviors include dietary and physical activity choices, while social networks dynamics include connections to family and friends, which may also influence individual behaviors. The environmental scale includes food availability, green and safe spaces for physical activity, access to supermarkets and neighborhood safety. Larger societal forces include economics, policy, education, health awareness, and culture. Each of these scales has different factors either directly or indirectly associated with obesity (Lee et al., 2017).

Tomer (2011) in his research indicates that socioeconomic groups with low personal capital, low health capital, and low social capital have higher obesity rates than socioeconomic groups with higher endowments of these intangible forms of capital. This has been supported by other studies that indicates that higher diet quality, as measured by the Healthy Eating Index, is associated with higher incomes, more education, and with lower rates of obesity and overweight (Henderson, 2007).

In developing countries such as Turkey, Brazil, Lebanon, and South Africa, obesity rates among adults show a strong correlation $\left(\mathrm{R}^{2}\right.$ is between 0.80-0.96) with a growing GDP per capita (Seydel et al., 2016). They revealed that Turkey, Brazil, and Lebanon are on the track of many developing countries with increasing Gross Domestic Product (GDP) and a parallel rise in obesity rates among less educated parts of the population. A wide body of literature suggests that there is a positive relationship between income and health (Smith, 1999), within and between countries (Marmot, 1999), and across ages (Case et al., 2002). In addition, macroeconomic conditions, specifically economic cycles, have been used to explain health outcomes. Ruhm (2000) finds that economic recessions, as measured by unemployment rates, lead to better health. His analysis provides strong evidence that health improves when the economy temporarily deteriorates. Specifically, state unemployment rates are negatively and significantly related to total mortality and eight of the ten specific causes of fatalities, with suicides representing an important exception. However, in a later study (Ruhm, 2013), these results are found to be unstable over different time periods and not consistent across causes of death. Windarti et al. (2019) argued that health inequality and economic 
development have a non-linear relationship called the "Obesity Kuznets curve". Under the Obesity Kuznets curve, as income rises, weight gain occurs since individuals can afford excess food; thus, caloric imbalance leads to an increase in obesity rates (Koplan \& Dietz, 1999).

Grecu and Rotthoff (2015) further expand of the applications of the Kuznets curve to personal health specifically pertaining to obesity, which they label the "obesity Kuznets curve". They argue that as incomes rise, more resources become available to buy food, assuming that health is a normal good. As such, people consume more calories and obesity rates increase. However, as incomes continue to rise, personal health becomes a more valued asset and people decrease their obesity levels (increasing their health levels). They extend this literature by analyzing the link between income and obesity.

Grecu and Rotthoff (2015) used data from 1991 to 2010 to study the obesity rate among White Americans with the assumption of higher obesity rate among Black Americans groups. However, their data could be distorted. Other studies have found that White American women face more social pressure concerning obesity than their male counterparts (Cawley, 2004). Specifically, Grecu and Rotthoff (2015) find evidence of an "obesity Kuznets curve" for White females in the United States but not for White males, possibly because females are more likely to be socially punished for obesity. Their findings reveal that obesity first increases as incomes rise. As people get out of poverty, their higher incomes allow them to increase their caloric intake, by increasing the amount of food or the density of the food consumed. It is also possible that as their incomes rise, they exercise less, travel by car instead of walking, or take a sedentary job rather than being active throughout the day. However, as incomes rise above a certain level, their ability to purchase and consume healthier food increases, and possibly their ability to increase physical activities improves their health, thus decreasing their obesity levels.

Aydin (2019) in his study also investigated to see whether obesity could be caused by economic growth. The results confirmed that economic growth is not a factor that may cause obesity in the group of to 20 obese countries from 1991 to 2016 that they examined.

Lowering obesity is critical for developing countries as it can contribute to higher economic growth and lower government costs. Research conducted by Aghion et al. (2010) utilized a cross-country regression analysis over the period 1960-2000 to investigate the relationship between health and economic growth as measured by GDP per capita in light of modern endogenous growth theory. The researchers found that both a higher initial level of life expectancy and a higher rate of improvement in life expectancy have a significantly positive impact on per capita GDP growth. The primary reasons for these findings are that individuals with higher life expectancy are more likely to save more and savings, in turn, contribute back into capital accumulation, and therefore, into GDP growth (Aghion et al., 2010). In addition, individuals with higher life expectancy are more likely to invest (or have parents who invest) in education, which in turn paves the way for a higher paying career (Aghion et al., 2010). Finally, on a direct basis, healthier individuals are typically more productive, better at creating and adapting to new technologies, and generally more able to cope with the rapid changes that are characteristic of a high-growth environment (Howitt, 2005).

Economic development with technological advancement and higher productivity creates excess supply that leads to availability of inexpensive and delicious foods, pushing more sedentary lifestyles and less physical activity, thus causing the obesity epidemic (Lakdawalla \& Philipson, 2009). However, if health is a normal good, then rising income coupled with higher economic development enables people to consume more healthy foods and to spend more in their overall personal health, which eventually reduces obesity rates.

Analysis by Windarti et al. (2019) supports the argument that middle-income countries, many of which are currently enjoying high economic growth, may be facing risk of damage to people's health and the related financial burden, requiring a strong initiative for health policy targeting obesity prevention. In addition, their results have suggested different types of social pressure in regard to being overweight between males and females, i.e., concern regarding overweight is larger for females than for males as females are likely to experience more social pressure over obesity than males" (p. 34).

A study by Mulugeta et al. (2021) examined the impact of the coronavirus disease 2019 (COVID-19) pandemic lockdown on weight, overweight and obesity, and identify the critical factors associated with 
weight gain. At a safety net health system in Massachusetts, 11,534 adults were retrospectively followed within 3 months of the COVID-19 lockdown. The study found nearly half of the patients gained weight during the first lockdown in Massachusetts, women (46.1\%) more than men (40.6\%) (Mulugeta et al., 2021). They noticed significant portion of participants gained weight with some sub-group variation. Overall obesity and overweight rates also significantly increased post-lockdown among women but not men.

The increase in unhealthy weight gain during the recent pandemic correlated with sedentary lifestyle, decreased physical activities and exercise (Caputo \& Reichert, 2020), as well as increased stress and anxiety and related problematic eating behavior, like stress-eating and night time eating, all of which could be among contributing factors (Almandoz et al., 2020).

The COVID-19 pandemic is causing substantial morbidity and mortality, straining health care systems, shutting down economies, closing school districts, and asking people to maintain social distancing. Although the effects of COVID-19 on obese patients have not yet been thoroughly tested, it has been clearly shown that obese patients are potentially more vulnerable to COVID-19 and more contagious than normal or slightly overweight patients (Abdalazim \& Albahir, 2020). Another study shows that obesity is linked to a variety of comorbid conditions that have been shown to be associated with increased morbidity and mortality from COVID-19 (Zhang, C. \& Magdy B. A, et al, 2020). Another noteworthy point is that the United States, which currently has the highest mortality rates from COVID-19, has a high prevalence of obesity compared to China when obesity is defined by BMI (Hu \& Jia, 2018).

\section{Poverty and Obesity}

In Peru, the official poverty definition supported by the National Institute of Statistics and Informatics (INEI, 2000) uses the poverty line method for consumption. The value of all the goods and services consumed by household is incorporated, regardless of the form of acquisition or attainment. The use of consumer spending has the advantage as the best indicator to measure well-being because it refers to what a household consumes and not what it can potentially consume when measured by income. Another favorable aspect is that consumption is one more variable stable income, which allows better measurement of the poverty level trend.

In the estimates of consumption expenditure, all sources of expenditure are considered. This includes monetary expenditure, as well as the various forms of acquisition of goods and services that do not imply a monetary payment of part. This last group includes self-consumption and self-supply, as well as in-kind payments that come from households' economic activities and also the elements of expenditure received by transfers from other households or by part of public and private organizations. Likewise, within the components of expenditure, expenses in health and public education are excluded, due to the lack of adequate prices to value said services consumed by households. Finally, the imputation for the consumption of river water or ditch is also excluded, because the degree of transformation of said goods is almost nil and there is no commercial value that allows an adequate valuation (INEI, 2018).

Last year, almost a third of the people in Latin America experienced either severe or moderate food insecurity according to the report. Moderate food insecurity means that they were forced to reduce the size of their meals, skip meals or to substitute lower quality ingredients. Severe food insecurity is when individuals go days without eating at all (Beaubien, 2020). Berdegué says the hunger problem in Latin America isn't about a lack of food:

In Latin America there is hunger, there is food insecurity and there is malnutrition because of a lack of purchasing power... It's because millions and millions of families lack money. Hunger in Latin America fundamentally is an expression of poverty and economic inequality (Beaubien, 2020).

Even the problem of obesity in the region is often concentrated among people who are economically poor. They often end up overweight because their diets are dominated by inexpensive, calorie-rich processed foods (Beaubien, 2020). Miguel Barreto, the regional director for the World Food Program, says Latin America is facing a "pandemic of hunger." Last year 47 million people in the region were classified as hungry, according to this year's report, with another 190 million listed as food insecure (Beaubien, 2020). 
At the same time, there is an obesity problem. The number of people deemed to be carrying too many extra pounds continues to rise throughout the region. Last year nearly $60 \%$ of adults in Latin America and the Caribbean were overweight. This is $20 \%$ higher than the global average. The rates are worse among women than men. Even children are suffering from "sobrepeso", or overweight, with $7.5 \%$ of children classified as overweight (Beaubien, 2020).

Peru has historically been one of the poorest and most unequal countries in Latin America. Sustained economic growth caused poverty and extreme poverty to fall sharply in the last ten years (World Bank, 2017). However, poverty is unevenly distributed - only 180 out of more than 1,800 district municipalities account for half of all poverty in the country, and districts with the highest poverty incidence are located mostly in the Sierra and Selva (World Bank, 2018). Peru's middle class is slightly smaller today than it was in 2011 according to a study by Lima's Chamber of Commerce (Peru Reports, 2015). According to Peru Reports (2015) the seven Peruvian regions which registered smaller middle classes include Huancavelica, Pasco, Amazonas, Piura, Ucayali, Cajamarca and Madre de Dios. On the other hand, four regions which saw slight increases in the size of their middle class included Ayacucho, Tumbes, San Martin, and Junin. Likewise, of the 9.1 million Peruvians who belong to the middle class (according to IEDEP's definition), over half live in Lima and Callao, and 20\% live in Arequipa, La Libertad, Piura, and Cusco. Obesity is an increasing public health concern in several developing countries, including Peru. An analysis of Demographic and Health Survey (DHS) 1996 showed a 9.4\% prevalence of obesity in Peruvian women. Data from the DHS 2008 showed a $14.3 \%$ prevalence of obesity, which is an increase of $52 \%$ in obesity rates in Peruvian women (Poterico et al., 2012).

Several authors have offered explanations for the increase in adolescent obesity in Latin America. Martorell et al. (1998) have noted that the traditional diet of the region has undergone extensive modification such that it now resembles the high-fat, high-calorie diets consumed in industrialized societies. The researchers speculate that consumption of high-calorie diets and a more sedentary lifestyle have resulted in an increase in obesity and obesity-related degenerative disorders in the region (Martorell et al., 1998). Troiano and Flegal (1998) have observed that the increases in obesity worldwide are due to social and environmental factors including changes in parental employment patterns, increased television viewing, concerns about neighborhood safety, and the proliferation of video games. Findings from the present study conducted by this work suggest that another contributing factor of the adolescent obesity prevalence in Latin America is a deficit in obesity knowledge in this age group.

McArthur et al. (2001) examined the effects of socioeconomic status (SES) on the obesity knowledge of adolescents in six Latin American cities. They found out that the weakest knowledge areas among youth from the higher SES groups were food preparation methods and the relationship between obesity and health, while those for adolescents from the lower SES groups were the fat and calorie content of foods and beverages and the relationship between obesity and health (McArthur et al., 2001). Classroom instruction about obesity was generally more available to students from the higher SES groups. The majority of adolescents from both SES groups were interested in learning more about weight loss methods, energy expenditure, and the fat and calorie content of foods and beverages.

The relationship between obesity and poverty has become more obvious and complex; being poor in one of the poorest countries may be associated with poor nutrition, while being poor in a developed country could mean a higher risk of obesity. This concept is confirmed by Sobal and Stunkard (1989) who found that in developed countries, there is an inverse relationship between obesity and socioeconomic status. In such countries, the higher social classes can compensate for a sedentary lifestyle, with more health information and athletic opportunities, plus they can afford better quality food which is organic and less processed. In less developed countries, or those with a \$2,500 GDP per capita, a direct relationship prevails, and excess weight is observed more frequently among the higher social classes (Monteiro et al. 2004).

\section{Peru Economic Conditions}

According to the National Institute of Statistics and Informatics and the World Bank, Peru is an uppermiddle income country with an estimated 2017 population of 32 million people. Peru's per capita Gross 
National Income (GNI) during the same year was \$5,960 (The World Bank, Peru, 2019). Additionally, 6.9 million, or $44 \%$, live in poverty with about $21.7 \%$ of the population living below the poverty line (The World Bank, Peru, 2019).

Existing studies suggest that the high cost of healthier diets may contribute to the obesity epidemic, especially among the lower-income and low-educated groups (see Table 1). Additionally, Table 1 shows that for the Peruvian case, higher obesity rates are presented as the age range increases. Likewise, obesity rates are higher in urban areas compared to the rural areas. Finally, obesity rates show a higher percentage in the coast region compared to the rates registered in the mountain range and jungle regions. According to the overweight/obesity rates presented in Table 1, the percentage of obese individuals during $2008-2020$ has been greater for those in higher wealth quintiles. In 2008, the obesity rate for those in the higher quintile was $16.2 \%$ as compared to $4 \%$ for those in the lower quintile, whereas in 2020 these percentages were $21.5 \%$ and $22.3 \%$, respectively. This data indicates that the obesity rate has increased for both upper- and lower-income quintiles, but it has increased at a much higher pace at the lower quintile. This data is inconsistent with Lakdawall and Philipson's (2002) findings that obesity and poor health status are very much a problem of low-income status. Other studies highlight the role that has been played by such determinants as agricultural modernization, technological innovation in food production, the economic crisis, globalization, and the liberalization of trade (Torres, 2012). With regard to the latter factor, it has been noted that the existence of economies that import products such as high-calorie industrialized foods with a significant sugar and fat content and which are low in unrefined carbohydrates, has produced changes in eating patterns, resulting in an increase in excess weight and obesity in broad sectors of the population. At the same time, observers have warned that income reduction has led many families to adopt new spending strategies which are also, to a great extent, a result of imitating external patterns and of persuasive action exerted by food companies via advertising.

TABLE 1

PERCENTAGE OF OBESE WOMEN BETWEEN 15-49 YEARS OLD BY CHARACTERISTICS, 2008 AND 2020

\begin{tabular}{|c|c|c|c|c|c|c|}
\hline \multirow{2}{*}{$\begin{array}{l}\text { Overweight/Obesity } \\
\text { Selected } \\
\text { Characteristic }\end{array}$} & \multicolumn{3}{|c|}{2008} & \multicolumn{3}{|c|}{2020} \\
\hline & $\begin{array}{l}>=25,0 \\
\text { Total } \\
\text { Overweight } \\
\text { / Obesity } \\
\end{array}$ & $\begin{array}{l}25,0-29,9 \\
\text { Only } \\
\text { Overweight }\end{array}$ & $\begin{array}{l}>=30,0 \\
\text { Only } \\
\text { Obesity }\end{array}$ & $\begin{array}{l}>=25,0 \\
\text { Total } \\
\text { Overweight } \\
\text { / Obesity } \\
\end{array}$ & $\begin{array}{l}25,0-29,9 \\
\text { Only } \\
\text { Overweight }\end{array}$ & $\begin{array}{l}>=30,0 \\
\text { Only } \\
\text { Obesity }\end{array}$ \\
\hline \multicolumn{7}{|l|}{ Residence Area } \\
\hline Urban & 52.1 & 35.4 & 16.7 & 64.9 & 37.7 & 27.2 \\
\hline Rural & 40.9 & 31.9 & 9.0 & 62.9 & 39.5 & 23.4 \\
\hline \multicolumn{7}{|l|}{ Natural Region } \\
\hline Coast & 54.0 & 35.3 & 18.7 & 65.6 & 37.5 & 28.2 \\
\hline Mountain Range & 44.5 & 33.5 & 11.0 & 62.2 & 39.6 & 22.6 \\
\hline Jungle & 43.7 & 32.1 & 11.6 & 62.8 & 37.5 & 25.3 \\
\hline \multicolumn{7}{|l|}{ Age } \\
\hline $15-19$ & 20.7 & 18.5 & 2.2 & 30.2 & 23.6 & 6.6 \\
\hline $20-29$ & 40.3 & 31.7 & 8.6 & 54.8 & 35.7 & 19.1 \\
\hline $30-39$ & 60.3 & 41.4 & 18.9 & 74.8 & 43.1 & 31.7 \\
\hline $40-49$ & 68.7 & 42.1 & 26.6 & 84.0 & 43.0 & 41.0 \\
\hline
\end{tabular}




\begin{tabular}{|l|l|l|l|l|l|l|}
\hline Level of Education & & & & & & \\
\hline Without Education & 49.9 & 39.0 & 10.9 & 75.8 & 41.6 & 34.2 \\
\hline Primary Education & 53.1 & 35.4 & 17.7 & 76.8 & 41.5 & 35.4 \\
\hline Secondary Education & 48.9 & 34.1 & 14.8 & 64.0 & 36.0 & 27.9 \\
\hline Higher Education & 45.8 & 33.7 & 12.1 & 61.0 & 38.9 & 22.0 \\
\hline Wealth Quintile & & & & & & \\
\hline Lower Quintile & 32.8 & 28.8 & 4.0 & 61.5 & 39.2 & 22.3 \\
\hline Second Quintile & 41.6 & 32.5 & 9.1 & 67.5 & 38.1 & 29.4 \\
\hline Intermediate Quintile & 51.2 & 35.1 & 16.1 & 66.8 & 35.8 & 31.0 \\
\hline Fourth Quintile & 55.4 & 37.2 & 18.2 & 66.2 & 38.3 & 27.9 \\
\hline Higher Quintile & 50.5 & 34.5 & 16.2 & 60.2 & 38.7 & 21.5 \\
\hline Total & $\mathbf{4 9 . 1}$ & $\mathbf{3 4 . 4}$ & $\mathbf{1 4 . 6}$ & $\mathbf{6 4 . 5}$ & $\mathbf{3 8 . 0}$ & $\mathbf{2 6 . 6}$ \\
\hline
\end{tabular}

Note: From Family Health and Demographic Survey (ENDES), 2008-2020.

\section{METHODOLOGY}

The empirical analysis investigated to capture the fundamental linkage between obesity, economic growth, and poverty for the 24 regions of Peru during the period 2008-2020 using statistical information from the Family Health and Demographic Survey (ENDES), the Regional Decision-Making System (SIRTOD), and the National Household Survey on Living Conditions and Poverty (ENAHO). We used econometric tools, the Granger causality test in panel data, a dynamic panel data analysis, and a cointegration analysis in panel data to test our data.

\section{Sources of Information}

For the purposes of this research, three sources of statistical information were used. Specific, statistical information from the Family Health and Demographic Survey (ENDES), the Regional Decision-Making System (SIRTOD), and the National Household Survey on Living Conditions and Poverty (ENAHO). Regarding the first source of information, it should be noted that the ENDES reports statistical data corresponding to obesity rates for women between 15 and 49 years old from each of the regions of Peru. Thus, based on the information available in the ENDES, for the purposes of this research, the obesity rate was approximated through the rate of obese women between 15 and 49 years old. On the other hand, from the second source, the information corresponding to the Gross Domestic Product per capita (GDPPC) in real terms using the base year of 2007. Finally, from the third source of information, the information corresponding to the poverty rate for women between 15 and 49 years old was collected, according to the age range reported by the ENDES on obesity.

\section{Granger Causality Test in Panel Data}

In order to identify and analyze the causal relationship of the quantitative variables (obesity, economic growth and poverty) under study, we used the test of Dumitrescu and Hurlin (2012) (DH test), who, based on the Granger (1969) causality test applied to time series, developed an extension to detect causality in panel data. Under the DH test, the underlying regression is:

$Y_{i, t}=\alpha_{i}+\sum_{k=1}^{K} \gamma_{i k} Y_{i, t-k}+\sum_{k=1}^{K} \beta_{i k} X_{i, t-k}+\varepsilon_{i, t}$

with $\mathrm{i}=1, \ldots, \mathrm{N}$ and $\mathrm{t}=1, \ldots, \mathrm{T}$, where $\mathrm{i}$ represents to each of the 24 regions of Peru, while $\mathrm{t}$ represents the horizon under study, i.e. data between 2008-2020. Likewise, $\mathrm{k}$ represents the optimal delay of the test that goes from $\mathrm{k}=1$ to $\mathrm{K}$ and which is determined from the Bayesian information criteria (BIC) in Stata. On the other hand, Y represents the obesity rate of Peruvian women between 15 and 49 years old for region 
variable, while $\mathrm{X}$ represents the explanatory variables economic growth (measured as the logarithm of the Gross Domestic Product per capita) and the poverty rate. Likewise, the aforementioned test establishes as a null hypothesis:

$H_{0}=\beta_{1 t}=\cdots=\beta_{i k}=0$

This corresponds to the absence of causality for all regions in the panel. So then, under the acceptance of the hypothesis it is confirmed that $\mathrm{X}$ does not cause the Granger to $\mathrm{Y}$, while under the rejection of the hypothesis it is confirmed that $\mathrm{X}$ causes the Granger to $\mathrm{Y}$. Finally, it is convenient to indicate that for the contrast of the hypothesis of the DH test, the average Wald statistic (López \& Weber, 2017).

\section{Dynamic Panel Data Analysis}

Our analysis consists of estimating the following dynamic panel data econometric model:

$$
\begin{aligned}
& \text { Obesity }_{i t}=\varphi * \text { Obesity }_{i t-1}+\beta_{1} * \operatorname{Ln}\left(G D P P C_{i t}\right)+\beta_{2} * \text { Poverty }_{i t}+\beta_{3} * d_{2015}{ }_{i t} \\
& +\beta_{4} * d_{2020}+\alpha_{i}+e_{i t}
\end{aligned}
$$

With expected signs as the following:

$$
\varphi>0, \beta_{1}>0, \beta_{2}>0, \beta_{3}<0 y \beta_{4}>0
$$

where Obesity is the obesity rate of Peruvian women between 15 and 49 years old for region, GDPPC is the Gross Domestic Product per capita in real terms, Poverty is the poverty rate for women between 15 and 49 years old, $\mathrm{d}_{2015}$ is a dummy variable that represents the Supreme Decree No. 007-2015-SA, and the coronavirus pandemic by which the regulation of technical parameters on processed foods and nonalcoholic beverages was approved in terms of sugar, sodium, and saturated fat content. This dummy variable takes the value of 1 for the years 2015-2020 and 0 for the years 2008-2014. Finally, the $d_{2020}$ is a dummy variable that represents the coronavirus pandemic and that for operationalization purposes takes the value of 1 for the year 2020 and 0 for the other years.

According to Zhang and Zhuang (2011), some econometric problems may arise from estimating Eq. (3). The first one results from unobserved time invariant individual-specific effects (fixed effect), such as geography and demographics, which may be correlated with the explanatory variables. The correlation between the explanatory variables and fixed effect leads to the Ordinary Least Square (OLS) estimator being biased and inconsistent. The second problem results from the presence of the lagged dependent variable and the potential endogeneity of explanatory variables. Since Obesity $\mathrm{it}_{\mathrm{it}}$ might be endogenous to the error terms through $\mathrm{e}_{\mathrm{it}}$, a problem of endogeneity exists and it will therefore be inappropriate to estimate the above by OLS (Zhang \& Zhuang, 2011, p.168).

Additionally, the variables economic growth such as poverty could also be endogenous due to the interaction that other explanatory factors of obesity may present (which have not been considered for the purposes of this research, based on the availability of complete and uniform information for each of the variables under study in the present investigation) with the aforementioned variables.

So then to solve these problems, Arellano and Bond (1991) propose the Generalized Methods of Moments (GMM) estimators, which takes the first differences of Eq. (3) and then the lagged levels of the right-hand-side variables are used as instruments in the first differenced equation (Zhang \& Zhuang, 2011, p.168). GMM overcomes the problems of potential endogeneity and unobserved country-specific effects in the data ensuring the best fit for panel data (Kavya \& Shijin, 2020, p.89).

\section{Cointegration Analysis in Panel Data}

In order to identify a long-term stable equilibrium relationship between obesity, economic growth, and poverty, a cointegration analysis was performed. In particular, for the purposes of this research, the 
cointegration tests in panel data by Kao (1999), Pedroni $(1999,2004)$ and Westerlund (2005) were used. In all the named tests, the common null hypothesis is that of no cointegration. The alternative hypothesis being that the variables are cointegrated in all the panels.

Thus, under the presence of cointegration, the presence of the phenomenon of spurious regression is ruled out, in such a way that the relationship between obesity, economic growth, and poverty corresponds to the movement and relationship between them, but it is not associated with a movement trend, which then validates the presence of a stable equilibrium relationship in the long term between obesity, economic growth, and poverty.

\section{Results}

In accordance with the methodological scheme proposed in the present investigation, in the first place, it begins with the Granger causality test in panel data. Thus, Table 2 shows the results corresponding to the causal relationship between obesity, economic growth, and poverty in the regions of Peru during the 20082020 period. In particular, a unidirectional relationship of economic growth towards obesity is verified, which is statistically significant at $1 \%$, which reveals that economic growth is highly relevant for obesity in the regions of Peru.

TABLE 2

PANEL CAUSALITY TEST

\begin{tabular}{|c|c|c|c|}
\hline Null Hypothesis & W-Stat. & Zbar-Stat. & Prob. \\
\hline LN_PBIPC does not homogeneously cause OBESITY & 4,25561 & 6,32597 & $0,0000 * * *$ \\
\hline OBESITY does not homogeneously cause LN_PBIPC & 0,97397 & $-0,66402$ & $i 067$ \\
\hline POVERTY does not homogeneously cause OBESITY & 2,95663 & 3,55911 & $0,0004 * * *$ \\
\hline OBESITY does not homogeneously cause POVERTY & 2,34729 & 2,26119 &, $0237 * *$ \\
\hline POVERTY does not homogeneously cause LN_PBIPC & 2,68695 & 2,98467 & $0,0028 * * *$ \\
\hline LN_PBIPC does not homogeneously cause POVERTY & 1,92026 & 1,35161 & 765 \\
\hline
\end{tabular}

$* * * * \mathrm{p}<0.01, * * \mathrm{p}<0.05, * \mathrm{p}<0.10$

Note. This test is performed through Dumitrescu and Hurlin (2012).

On the other hand, there is the existence of a two-way causal relationship between obesity and poverty. In this sense, within this bidirectional relationship it can be observed that poverty causes obesity in Granger, as well as that obesity causes poverty in Granger. The result associated with the causal relationship from poverty to obesity shows correspondence with that reported by Hojjat and Morocho (2019), that is, the reduction of poverty in Peru in the last 13 years has led to an increase in obesity in the women 15-49 years old. Poverty is thus a determinant of health outcome.

Finally, there is a causal relationship that goes from poverty to economic growth, which is statistically significant at $1 \%$, revealing that poverty is relevant for economic growth. This finding could in turn suggest that the main challenge to Peru's economic growth is how to improve existing poverty levels in its regions.

Having seen the results of the Granger causality test, it is appropriate to address the results of the dynamic panel data model. According to Table 3, it is observed that economic growth, poverty, Supreme Decree No. 007-2015-SA and the coronavirus pandemic are relevant to explain the levels of obesity registered in the regions of Peru during the 2008-2020 period. Additionally, the statistical relevance of the obesity lag can also be corroborated, which in turn reveals that obesity is persistent, showing a permanent upward trend over time, as shown in Figure 2. 
TABLE 3

DYNAMIC PANEL DATA MODEL ${ }^{1}$

\begin{tabular}{|c|c|c|c|c|}
\hline \multicolumn{5}{|c|}{ Dependent variable (Obesity rate in Peruvian women between 15-49 years old) } \\
\hline Explanatory variable & Coefficient & $\begin{array}{l}\text { Robust } \\
\text { Deviation }\end{array}$ & Standard & Probability \\
\hline Obesity it-1 & 0.5318 & 0.0550 & & 0.0000 \\
\hline $\operatorname{Ln}\left(G_{D P P C}{ }_{i t}\right)$ & 1.1704 & 0.1602 & & 0.0000 \\
\hline Poverty & -0.0752 & 0.0278 & & 0.0070 \\
\hline $\mathrm{d}_{2015}$ & 1.7107 & 0.3308 & & 0.0000 \\
\hline$d_{2020}$ & 3.2990 & 0.6631 & & 0.0000 \\
\hline $\operatorname{AR}(2)$ & 0.6678 & & & \\
\hline Hansen Test & 0.7412 & & & \\
\hline Observations & 288 & & & \\
\hline Regions & 24 & & & \\
\hline
\end{tabular}

All the explanatory variables are statistically significant at $1 \%$, also when observing each of the estimators obtained, in the case of economic growth it is appreciated that in the face of an increase of $1 \%$ of GDP per capita, the obesity rate increases by $1.17 \%$, while in the case of the poverty rate it is observed that with a reduction of one percentage point in the poverty rate, obesity increases by $0.08 \%$.

On the other hand, the results associated with $\mathrm{d}_{2015}$ reveal that the regulation associated with the technical parameters on processed foods and non-alcoholic beverages referring to the content of sugar, sodium, and saturated fat, would not have achieved as a result the reduction of obesity but rather it have led to an increase in obesity. A similar result is shown by the variable $d_{2020}$, the results of which allow corroborating that in the context of the coronavirus pandemic, the obesity rate in the regions of Peru has increased.

Compared to the empirical work of Windarti et al. (2019), whose econometric specification is similar to that used in this research, the results obtained within show a linear relationship between obesity and economic growth, while the aforementioned authors show a non-linear quadratic relationship. Likewise, they identify that for every $1 \%$ increase in GDP per capita, obesity increases by $2.48 \%$ points, while in the case of our investigation, the impact is $1.17 \%$. Thus, the linear relationship that exists in the regions of Peru between obesity and economic growth reveals that this country is located in the first section of the Kuznets Obesity curve, as an underdeveloped country or not considered as a high-income country.

This finding in turn suggests taking into account that for low-income countries, as incomes increase, the weight-related health status deteriorates; thus, an increase in income raises the health risk (Windarti et al., 2019). Likewise, Windarti et al. (2019) note that a strong health policy initiative aimed at obesity prevention is required for low- and middle-income countries, many of which are currently experiencing high economic growth. In this sense, in a country like Peru, which in terms of the relationship between obesity and economic growth is located in the first section of the Kuznets Obesity curve, it requires public policy instruments that allow reduction of the existing levels of obesity in its regions to thereby avoid the health risks derived from obesity.

In relation to the finding of the poverty rate, the results obtained are consistent with our previous study (Hojjat \& Morocho, 2019) that for the period 2008 - 2017, the regions of Peru reported an inverse and statistically significant association between the obesity rate and the poverty rate. This result reinforces the arguments of Windarti et al. (2019), i.e., obesity rates are positively associated with an increase in income in underdeveloped countries (or low-income countries such as Peru), while in developed (high-income) countries, obesity is inversely associated with an increase of the incomes. 
Regarding regulation of Supreme Decree No. 007-2015-SA, it is appropriate to justify that in the regions of Peru, the regulations that establish technical parameters on food are not sufficient to achieve a reduction in obesity rates per se, unless if they are combined with other public policy instruments. Thus, according to Chan (2013), government's role through state legislation is only one approach within a web of many other spheres of influence demonstrated in the socio-ecological model. In this sense, for the Peruvian case it is necessary to focus on new strategies that lead to better results in reducing the obesity. Finally, in relation to the COVID-19 pandemic, the data reported in Figure 2 show that, in the context of the current pandemic, the confinement measures to deal with it would have led to an increase in obesity rates.

Indeed, one of the consequences of quarantine-induced stress is a change in lifestyle and eating habits leading to obesity (Mattioli et al., 2020). Likewise, Mattioli and Ballerini (2020) as well as Abbas et al. (2020) point out that although little is known about the effects of quarantine on obesity, this period leads to severe stress and stress can be linked to an increased risk of obesity. So then, it is very possible that women of 15-49 years old in Peru have neglected their healthy eating habits as well as physical activity during the quarantine period in the context of the coronavirus pandemic, which consequently it resulted in higher levels of obesity.

Finally, as the last instrument of econometric analysis, it is necessary to address the results of the analysis of cointegration of panel data for the variables obesity, economic growth, and poverty, which is shown in Table 4. In particular, the results obtained in the analysis of cointegration confirm that for the three tests used, there exists a stable equilibrium relationship in the long-term between the variables obesity, economic growth, and poverty. Therefore, the presence of a spurious relationship between the mentioned variables can be ruled out. Thus finally, it can be concluded that in the long-term, both economic growth and poverty constitute drivers for obesity reduction.

\section{TABLE 4 \\ PANEL DATA COINTEGRATION ANALYSIS: OBESITY, ECONOMIC GROWTH, AND POVERTY}

\begin{tabular}{llcc}
\hline \hline Statistical / Cointegration Test / Probability & Kao(a) & Pedroni(b) & Westerlund(c) \\
\hline \hline Modified Dickey-Fuller t & 0.0027 & & \\
Dickey-Fuller t & 0.0000 & & \\
Augmented Dickey-Fuller t & 0.0000 & 0.3129 & \\
Unadjusted modified Dickey-Fuller t & 0.1965 & & \\
Unadjusted Dickey-Fuller t & 0.0111 & & \\
Modified Phillips-Perron t & & 0.0028 & \\
Phillips-Perron t & & 0.2876 & 0.0080 \\
Variance Ratio & & \\
\hline \hline
\end{tabular}

Note. (a) and (b): Null hypothesis $\left(\mathrm{H}_{0}\right)$ : No cointegration, Alternative hypothesis $\left(\mathrm{H}_{1}\right)$ : All panels are cointegrated. (c): Null hypothesis $\left(\mathrm{H}_{0}\right)$ : No cointegration, Alternative hypothesis $\left(\mathrm{H}_{1}\right)$ : Some panels are cointegrated.

In summary, in terms of causality for the regions of Peru during the $2008-2020$ period, the existence of a unidirectional causal relationship of economic growth towards obesity is confirmed. On the other hand, the causal relationship presented by the obesity and poverty variables is bidirectional. Finally, a unidirectional causal relationship from poverty to economic growth is corroborated.

Additionally, the results associated with the dynamic panel data model reveal that the positive sign of the lag in the obesity rate confirms the persistence that this variable has registered during the 2008-2020 period. Likewise, improvement of the poverty of Peruvian women has led to a worsening of obesity. On the other hand, it is verified that higher economic growth increases obesity levels, in the same way it occurs that the regulations that establish technical parameters on food and the quarantine period in the context of the coronavirus pandemic also have increased obesity rate. 
A final point to note is that obesity, economic growth, and poverty present a stable equilibrium relationship in the long term, i.e., these variables respond to variations in their behavior but not to a trend effect, which then confirms the role prevailing both economic growth and poverty to explain obesity rates in the regions of Peru.

\section{REFERENCES}

Abbas, A.M., Fathy, S.K., Fawzy, A.T., Salem, A.S., \& Shawky, M.S. (2020). The mutual effects of COVID-19 and obesity. Obes. Med. https://doi.org/10.1016/j.obmed.2020.100250

Abdalazim, A., \& Albashir, D. (2020). The potential impacts of obesity on COVID-19. Clinical Medicine, 20(4), e109-e113. doi: 10.7861/clinmed.2020-0239

Aghion, P., Howitt, P., \& Murtin, F. (2010). The relationship between health and economic growth: When Lucas Meets Nelson-Phelps. Working Paper 15813, National Bureau of Economic Research. Retrieved from http://www.nber.org/papers/w15813

Ahmad, Q.I., Ahmad, C.B., \& Ahmad. S.M (2010). Childhood obesity. Indian J Endocrinol Metab., 14(1), 19-25.

Almandoz, J.P., Xie, L., Schellinger, J.N., Mathew, M.S., Gazda, C., Ofori, A., . . Messiah, S.E. (2020). Impact of COVID-19 stay-at-home orders on weight-related behaviours among patients with obesity. Clin Obes., 10(5), e12386. doi:10.1111/cob.12386

Anderson, P.M., \& Butcher, K.F. (2006). Children obesity: Trends and potential causes. JSTOR, 16(1). Retrieved from https://www.jstor.org/stable/3556549?seq=1

Arellano, M., \& Bond, S. (1991). Some Tests of Specification for Panel Data: Monte Carlo Evidence and an Application to Employment Equations. The Review of Economic Studies, 58(2), 277-297. https://doi.org/10.2307/2297968

$\mathrm{Au}$, N., \& Johnston, D.W. (2014). Too much of a good thing? Exploring the impact of wealth on weight. Health Economics, 24, 1403-1421.

Aydin, M. (2019). The effect of economic growth on obesity for the most obese countries: New evidence from the obesity Kuznets curve. The European Journal of Health Economics. https://doi.org/10.1007/s10198-019-01099-2

Beaubien, J. (2020, December 9). Latin America is facing a hunger pandemic. Retrieved December 9, 2020, from https://www.npr.org/sections/goatsandsoda/2020/12/09/943906342/latin-america-isfacing-a-hunger-pandemic?

Caputo, E.L., \& Reichert, F.F. (2020, November 3). Studies of Physical Activity and COVID-19 During the Pandemic: A Scoping Review. J Phys Act Health, 17(12), 1275-1284. doi: 10.1123/jpah.2020-0406. PMID: 33152693

Case, A., Lubotsky, D., \& Paxson, C. (2002). Economic status and health in childhood: The Origins of the gradient. American Economic Review, 92(5), 1308-34.

Cawley, J. (2004). The impact of obesity on wages. Journal of Human Resources, 39(2), 451-474.

Chan, S. (2013). Fighting Obesity in the United States with State Legislation. RAND Corporation. Retrieved from https://www.rand.org/pubs/rgs_dissertations/RGSD324.html

Devaux, M., \& Sassi, F. (2013). Social inequalities in obesity and overweight in 11 OECD countries. Eur J Public Health, 23, 464-9.

Dinsa, G.D., Goryakin, Y., Fumagalli, E., \& Suhrcke, M. (2012). Obesity and socioeconomic status in developing countries: A systematic review. Obesity Reviews, 13, 1067-1079. doi: 10.1111/j.1467-789X.2012.01017.x

Dumitrescu, E-I., \& Hurlin, C. (2012). Testing for Granger non-causality in heterogeneous panels. Economic Modelling, 29(4), 1450-1460. https://doi.org/10.1016/j.econmod.2012.02.014

Friedman R.R., \& Puhl, R.M. (2012). Rudd Report: Weight bias, a social justice issue, a policy brief.

Friedman School of Nutrition Science and Technology, Tufts University. (n.d.). Childhood Obesity Causes. ChildObesity180. Retrieved August 1, 2021, from https://childobesity180.org/ 
Granger, C. (1969). Investigating Causal Relations by Econometric Models and Cross-spectral Methods. Econometrica, 37(3), 424-438. https://doi.org/10.2307/1912791

Grecu, A.M., \& Rotthoff, K.W. (2015). Economic growth and obesity: Findings of an Obesity Kuznets curve. Applied Economics Letters, 22(7), 539-543. http://dx.doi.org/10.1080/13504851.2014.955251

Henderson, L.J. (2007). Obesity, Poverty and Diversity: Theoretical and Strategic Challenges. In J. Zoltan, Z. Acs, \& A. Lyles (Eds.), Obesity, business, and public policy (pp. 57-75). Cheltenham, UK: Edward Elgar.

Hojjat, T.A., \& Hojjat, R. (2017). The Economics of Obesity: Poverty, Income Inequality and Health. Springer.

Hojjat, T.A., \& Morocho, J. (2019). Obesity and Socioeconomic Status Among Peruvian Women: Evidence of Panel Data Analysis. Journal of Applied Business and Economics, 21(6). https://doi.org/10.33423/jabe.v21i6.2402

Howitt, P. (2005). Health, human capital, and economic growth: A Schumpeterian perspective in health and economic growth: Findings and policy implications, edited by G. López-Casasnovas, B. Rivera, \& L. Currais (pp. 19-40). Cambridge. MA: MIT Press.

Hu, C., \& Jia, W. (2018). Diabetes in China: Epidemiology and genetic risk factors and their clinical utility in personalized medication. Diabetes, 67, 3-11. [PubMed] [Google Scholar].

Iseri, A., \& Arslan, N. (2009). Obesity in adults in Turkey: Age and regional effects. Eur J Public Health, $19,91-4$.

Kao, C. (1999). Spurious regression and residual-based tests for cointegration in panel data. Journal of Econometrics, 90(1), 1-44. https://doi.org/10.1016/S0304-4076(98)00023-2

Kavya, T.B., \& Shijin, S. (2020). Economic development, financial development, and income inequality nexus. Borsa Istanbul Review, 20(1), 80-93. https://doi.org/10.1016/j.bir.2019.12.002

Kelly, T., Yang, W., Chen. C.S., Reynolds, K., \& He, J. (2008). Global burden of obesity in 2005 and projections to 2030. International Journal of Obesity, 32, 1431-1437.

Kinge, J.M., Strand, B.H., Vollset, S.E., \& Skirbekk, V. (2015). Educational inequalities in obesity and gross domestic product: Evidence from 70 countries. J Epidemiol Community Health.

Koplan, J.P., \& Dietz, W.H. (1999). Caloric imbalance and public health policy. JAMA, 282, 1579e81.

Lakdawalla, D., \& Philipson, T. (2002). The growth of obesity and technological Change: A theoretical and empirical examination. Working Paper (8946). National Bureau of Economic Research. Retrieved from http://www.nber.org/papers/w8946

Lakdawlla, D., \& Philipson, T. (2009). The growth of obesity and technological Change. Economics \& Human Biology, 7(3), 283-293.

Lee, B.Y., Bartsch, S.M., Mui, Y., Haidari, L.A., Spiker, M.L., \& Gittelsohn, J. (2017). A systems approach to obesity. Nutrition Reviews, 75(suppl 1), 94-106. https://doi.org/10.1093/nutrit/nuw049

Lopez, L., \& Weber, S. (2017). Testing for Granger Causality in Panel Data. The Stata Journal, 17(4), 972-984. https://doi.org/10.1177/1536867X1801700412

Ludwig, D.S., \& Rogoff, K.S. (2018, August 9). The Toll of America's Obesity: Beyond the human suffering, diet-related diseases impose massive economic costs. The New York Times. Retrieved October 23, 2019, from https://www.nytimes.com/2018/08/09/opinion/cost-diabetes-obesitybudget.html

Marmot, M. (1999). Epidemiology of socioeconomic status and health: Are determinants within countries the same as between countries? In N.E. Adler, M. Marmot, B.S. McEwen, \& J. Stewart (Eds.), Socioeconomic Status and Health in Industrial Nations. New York: The New York Academy of Sciences.

Martorell, R., Khan, L.K., Hughes, M.L., \& Grummer-Strawn, L.M. (1998). Obesity in Latin American women and children. Journal of Nutrition, 128, 1464-1473. 
Mattioli, A., \& Ballerini, M. (2020). Lifestyle at time of COVID-19, how could quarantine affect cardiovascular risk. Am. J. Lifestyle Med., 14(3), 240-242. https://doi.org/10.1177/1559827620918808

Mattioli, A., Pinti, M., Farinetti, A., \& Nasi, M. (2020). Obesity risk during collective quarantine for the COVID-19 epidemic. Retrieved from https://www.ncbi.nlm.nih.gov/pmc/articles/PMC7282788/\#!po=7.14286

McArthur, J. (2019, July 19). (Audio podcast) “What does a new UN report reveal about global hunger and obesity?” The Brooking Institutions. Retrieved July 19, 2019, from https://www.brookings. edu/podcast-episode/what-does-a-new-un-report-reveal-about-global-hunger-and-obesity/?

McArthur, L., Peña, M., \& Holbert, D. (2001). Effects of socioeconomic status on the obesity knowledge of adolescents from six Latin American. International Journal of Obesity, 25, 1262-1268. Nature Publishing Group.

Monteiro, C.A., Moura, E.C., Conde, W.L., \& Popkin, B.M. (2004). Socioeconomic status and obesity in adult populations of developing countries: A review. Bulletin of the World Health Organization, 82(12), 940-946.

Mulugeta, W., Desalegn, H., \& Solomon, S. (2021). Impact of the Covid-19 pandemic lockdown on weight status and factors associated with weight gain among adults in Massachusetts. Clinical Obesity, Wiley. Retrieved from https://onlinelibrary.wiley.com/doi/epdf/10.1111/cob.12453

National Household Survey on Living Conditions and Poverty - ENAHO. (n.d.). Retrieved from http://iinei.inei.gob.pe/microdatos/

National Institute of Statistics and Informatics, Peru - INEI. (2009). Demographic and Family Health Survey-ENDES, 2007-2008. [Internet]. Retrieved from https://dhsprogram.com/pubs/pdf/fr234/fr234.pdf/

National Institute of Statistics and Informatics, Peru - INEI. (2010). Demographic and Family Health Survey-ENDES, 2009. [Internet]. Retrieved from https://dhsprogram.com/pubs/pdf/FR242/FR242.pdf

National Institute of Statistics and Informatics, Peru - INEI. (2011). Demographic and Family Health Survey-ENDES, 2010. [Internet]. Retrieved from https://proyectos.inei.gob.pe/endes/2010/endes00/index.html

National Institute of Statistics and Informatics, Peru - INEI. (2012). Demographic and Family Health Survey-ENDES, 2011. [Internet]. Retrieved from https://proyectos.inei.gob.pe/web/biblioineipub/bancopub/Est/Lib1027/index.html

National Institute of Statistics and Informatics, Peru - INEI. (2013). Demographic and Family Health Survey-ENDES, 2012. [Internet]. Retrieved from http://proyectos.inei.gob.pe/web/biblioineipub/bancopub/est/lib1075/index.html

National Institute of Statistics and Informatics, Peru - INEI. (2014). Demographic and Family Health Survey-ENDES, 2013. [Internet]. Retrieved from https://www.inei.gob.pe/media/MenuRecursivo/publicaciones_digitales/Est/Lib1151/index.html

National Institute of Statistics and Informatics, Peru - INEI. (2015). Demographic and Family Health Survey-ENDES, 2014. [Internet]. Retrieved from https://www.inei.gob.pe/media/MenuRecursivo/publicaciones_digitales/Est/Lib1211/index.html

National Institute of Statistics and Informatics, Peru - INEI. (2016). Demographic and Family Health Survey-ENDES, 2015. [Internet]. Retrieved from https://www.inei.gob.pe/media/MenuRecursivo/publicaciones_digitales/Est/Lib1356/

National Institute of Statistics and Informatics, Peru - INEI. (2017). Demographic and Family Health Survey-ENDES, 2016. [Internet]. Retrieved from https://www.inei.gob.pe/media/MenuRecursivo/publicaciones_digitales/Est/Lib1433/index.html

National Institute of Statistics and Informatics, Peru - INEI. (2018). Demographic and Family Health Survey-ENDES, 2017. [Internet]. Retrieved from https://www.inei.gob.pe/media/MenuRecursivo/publicaciones_digitales/Est/Lib1525/index.html 
National Institute of Statistics and Informatics, Peru - INEI. (2019). Demographic and Family Health Survey-ENDES, 2018. [Internet]. Retrieved from

https://www.inei.gob.pe/media/MenuRecursivo/publicaciones_digitales/Est/Lib1656/index1.html

National Institute of Statistics and Informatics, Peru - INEI. (2020). Demographic and Family Health Survey-ENDES, 2019. [Internet]. Retrieved from

https://www.inei.gob.pe/media/MenuRecursivo/publicaciones_digitales/Est/Endes2019/

National Institute of Statistics and Informatics, Peru - INEI. (2021). Demographic and Family Health Survey-ENDES, 2020. [Internet]. 2021, Retrieved from

https://www.inei.gob.pe/media/MenuRecursivo/publicaciones_digitales/Est/Lib1795/

National Institute of Statistics and Informatics, Peru - INEI. (2021). Demographic and Family Health Survey-ENDES, 2020. [Internet]. Retrieved from https://www.inei.gob.pe/media/MenuRecursivo/publicaciones_digitales/Est/Lib1525/index.html/

National Institute of Statistics and Information Technology (INEI). (2018). Evolution of monetary poverty 2007-2017, 2018; P. 165. [Internet]. Retrieved May 20, 2019, from https://www.inei.gob.pe/ media/cifras_de_pobreza/informe_tecnico_pobreza_monetaria_2007-2017.pdf/

National Institute of Statistics and Information Technology (INEI). (2000). Methodology for measuring the poverty in Peru, [Internet]. Retrieved May 23, 2019, from https://www.inei.gob.pe/media/MenuRecursivo/metodologias/pobreza01.pdf

Pedroni, P. (1999). Critical Values for Cointegration Tests in Heterogeneous Panels with Multiple Regressors. Oxford Bulletin of Economics and Statistics, 61(S1), 653-670. Retrieved from https://onlinelibrary.wiley.com/toc/14680084/1999/61/S1

Pedroni, P. (2004). Panel Cointegration: Asymptotic and Finite Sample Properties of Pooled Time Series Tests with an Application to the PPP Hypothesis. Econometric Theory, 20, 597-625. doi:10+10170S0266466604203073

Peru Reports. (2015). Peru's middle class slightly smaller from four years ago. Retrieved from https://perureports.com/2015/06/16/perus-middle-class- down-slightly-over-four-years/

Peru Reports. (2018, May 20). Peru Reports. Retrieved from https://perureports.com/poverty-inequality/

Poterico. J.A., Stanojevic, S., Ruiz-Grosso, P., Bernabe-Ortiz, A., \& Miranda, J.J. (2012). The association between socioeconomic status and obesity in Peruvian women. Obesity (Silver Spring), 20(11), 2283-9. http://dx.doi.org/10.1038/oby.2011.288

Regional Decision-Making System - SIRTOD. (n.d). Retrieved from https://systems.inei.gob.pe/SIRTOD/

Ruhm, C.J. (2000) Are recessions good for your health? The Quarterly Journal of Economics, 115, 61750. doi: 10.1162/003355300554872

Ruhm, C.J. (2013). Recessions, healthy no more? NBER, Working Paper No. 19287, NBER, Cambridge, MA. doi: 10.3386/w19287

Seydel, S.G., Kucukoglu, O., Altinbas, A., Demir, O.O., Yilmaz, S., Akkiz, H., . . Canbay, A. (2016, September-October). Economic growth leads to increase of obesity and associated hepatocellular carcinoma in developing countries. Concise Review, 15(5), 662-672.

Smith, J.P. (1999). Healthy bodies and thick wallets: The dual relation between health and economic status. Journal of Economic Perspectives, 13(2), 145-167.

Sobal, J., \& Stunkard, A.J. (1989). Socioeconomic status and obesity: A review of the literature. Psychological Bulletin, 105(2), 260-275.

Stutzer, A. (2007). Limited self-control, obesity and the loss of happiness. Social Science Research Network, Discussion Paper, 2925, 10. Retrieved January 1, 2011, from http://papers.ssrn.com/sol3/papers.cfm?abstract_id=1001413

The World Bank. (2019). World development indicators. Peru. Retrieved from https://databank.bancomundial.org/data/source/world-development-indicators\#

The World Health Organization (WHO). (n.d.). Global Database on Body Mass Index. Retrieved from https://www.who.int/data/gho/data/themes/theme-details/GHO/body-mass-index-(bmi) 
The World Health Organization. (2020). Fact Sheet, Obesity \& Overweight. Retrieved from https://www.who.int/news-room/fact-sheets/detail/obesity-and-overweight

The World Health Organization. (2021, June 9). Obesity and Overweight. Media Centre. Retrieved June 10, 2020, from https://www.who.int/en/news-room/fact-sheets/detail/obesity-and-overweight

Tomer, J.F. (2011). What Causes Obesity? And Why Has It Grown So Much? Challenge, 54, $22-49$.

Torres, F. (2012). Transformaciones de la demanda alimentaria como factor de la obesidad en México. In J. Rivera, M. Hernández, C. Aguilar, \& C. Vadillo (Eds.), Obesidad en México. Recomendaciones para una política de Estado (pp. 125-144). México: UNAM, Google Scholar.

Troiano, R.P., \& Flegal, K.M. (1998). Overweight children and adolescents: Description, epidemiology, and demographics. Pediatrics, 101, 497-504.

Westerlund, J. (2005). New Simple Tests for Panel Cointegration. Econometric Reviews, 24(3), 297-316. https://doi.org/10.1080/07474930500243019

Wilkinson, R., \& Pickett, K. (2009). Why greater equality makes societies stronger: The spirit level. New York, NY: Bloomsbury Press.

Windarti, N.S.W., Hlaing, S.W., \& Kakinaka, M. (2019). Obesity Kuznets curve: International evidence. Public Health, 169, 25-35.

World Bank. (2017). Systematic Country Diagnostic. Perú. Retrieved from https://documents1. worldbank.org/curated/en/919181490109288624/pdf/Peru-SCD-final-3-16-17-03162017.pdf

Zhang, C., \& Magdy B.A. (2020, September 9). Factors Associated with Increased Morbidity and Mortality of Obese and Overweight COVID-19 Patients. Biology (Basel), 9(9), 280. doi:10.3390/biology9090280. PMID: 32916925; PMCID: PMC7564335

Zhuang, L. (2011). The composition of human capital and economic growth: Evidence from China using dynamic panel data analysis. China Economic Review, 22(1), 165-171. https://doi.org/10.1016/j.chieco.2010.11.001 


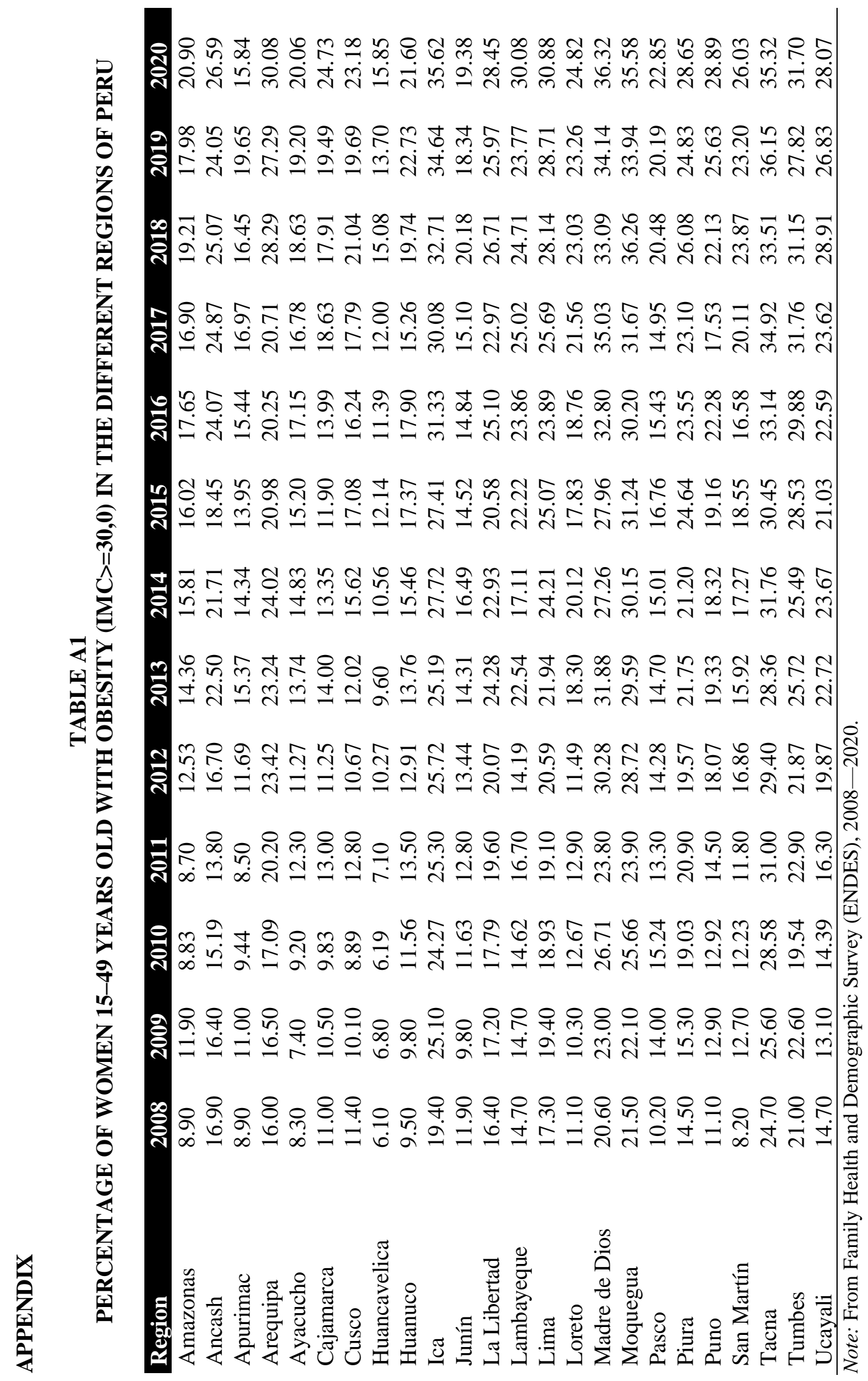


FIGURE A1

PERCENTAGE OF WOMEN 15-49 YEARS OLD WITH OBESITY (IMC >=30,0) BY NATURAL REGION (COAST)

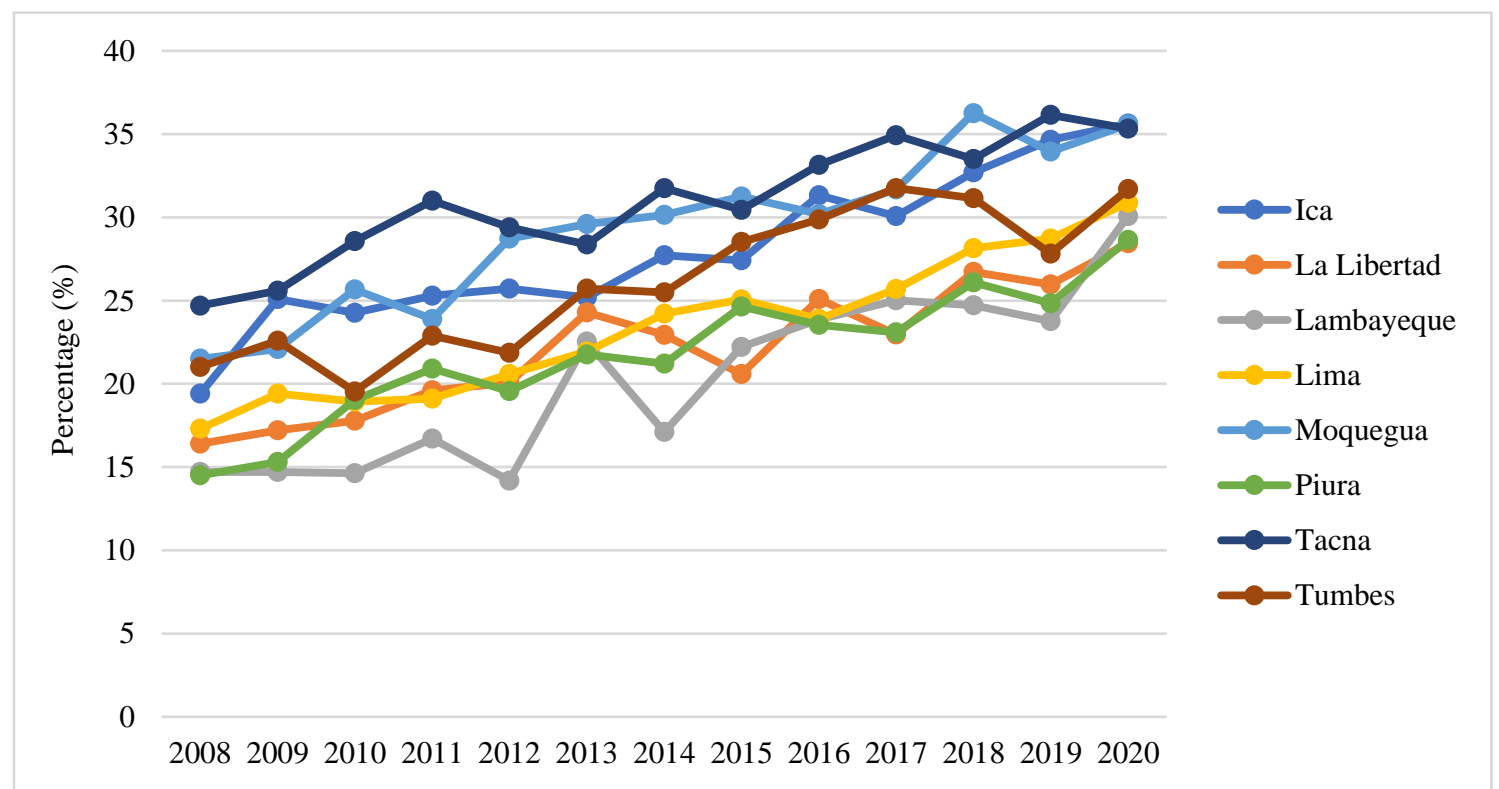

Note: From Family Health and Demographic Survey (ENDES), 2008-2020.

FIGURE A2

PERCENTAGE OF WOMEN 15-49 YEARS OLD WITH OBESITY (IMC >=30,0) BY NATURAL REGION (MOUNTAIN RANGE)

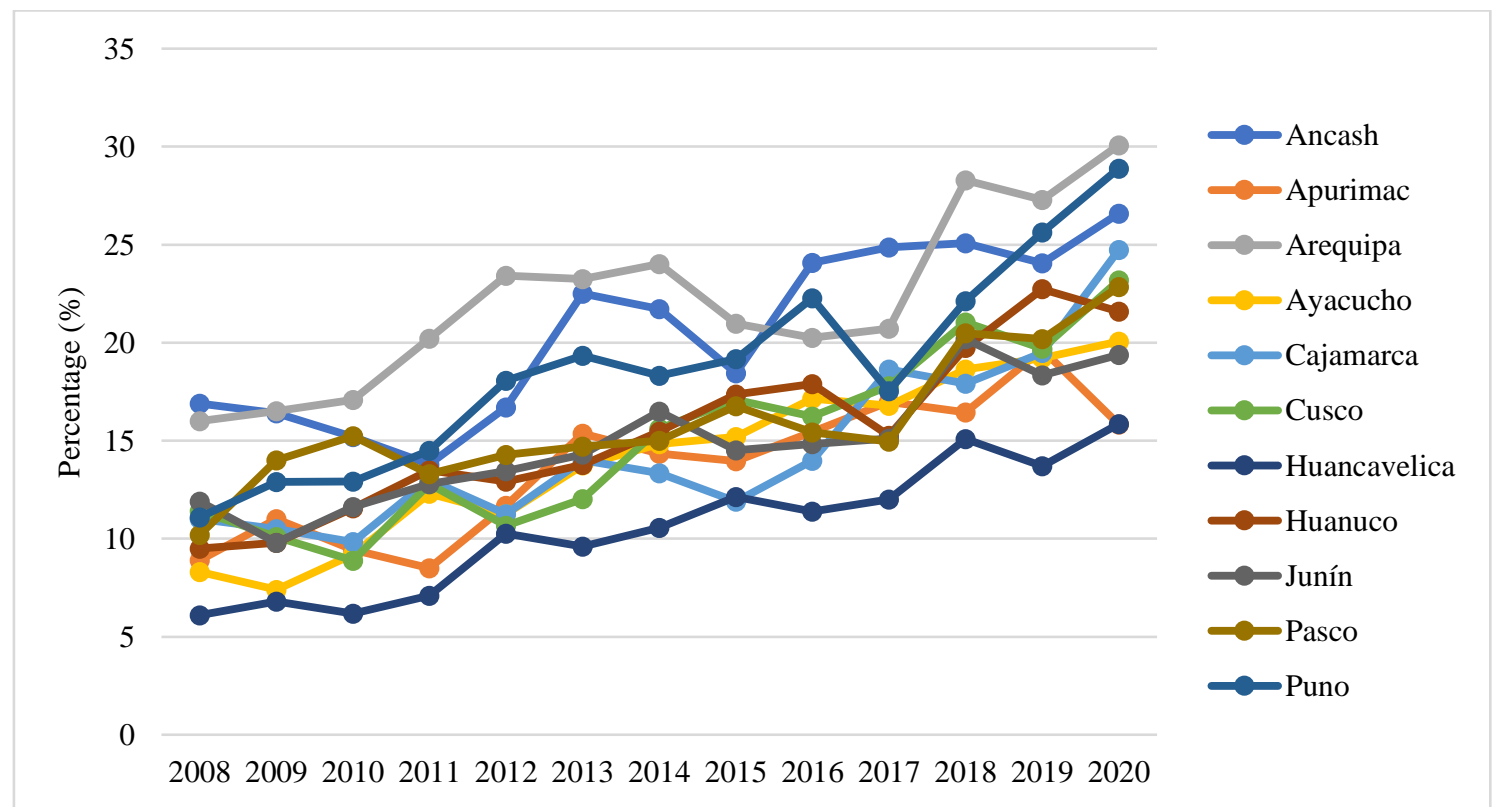

Note: From Family Health and Demographic Survey (ENDES), 2008-2020. 


\section{FIGURE A3 \\ PERCENTAGE OF WOMEN 15-49 YEARS OLD WITH OBESITY (IMC >=30,0) BY NATURAL REGION (JUNGLE)}

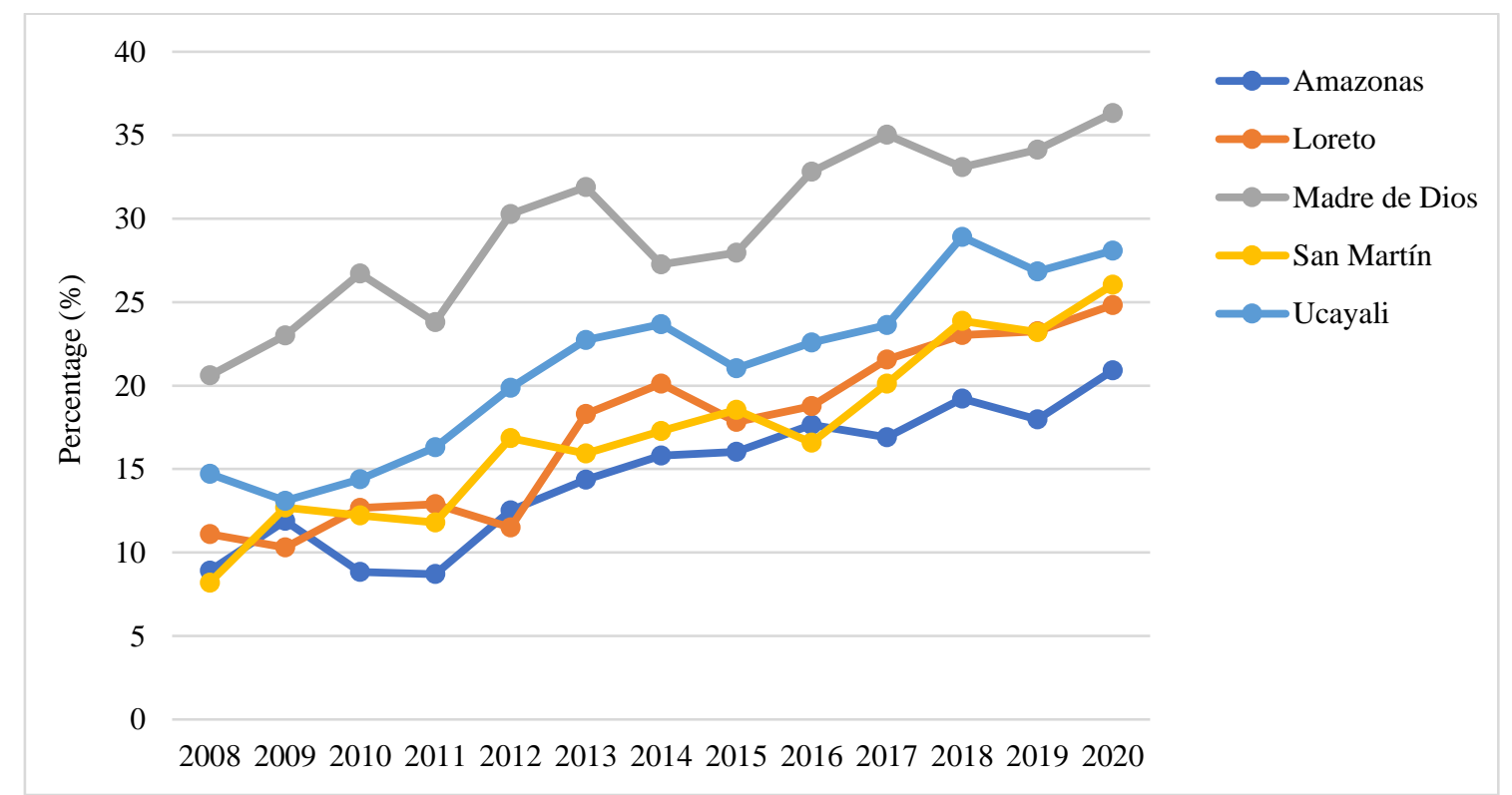

Note: From Family Health and Demographic Survey (ENDES), 2008-2020. 


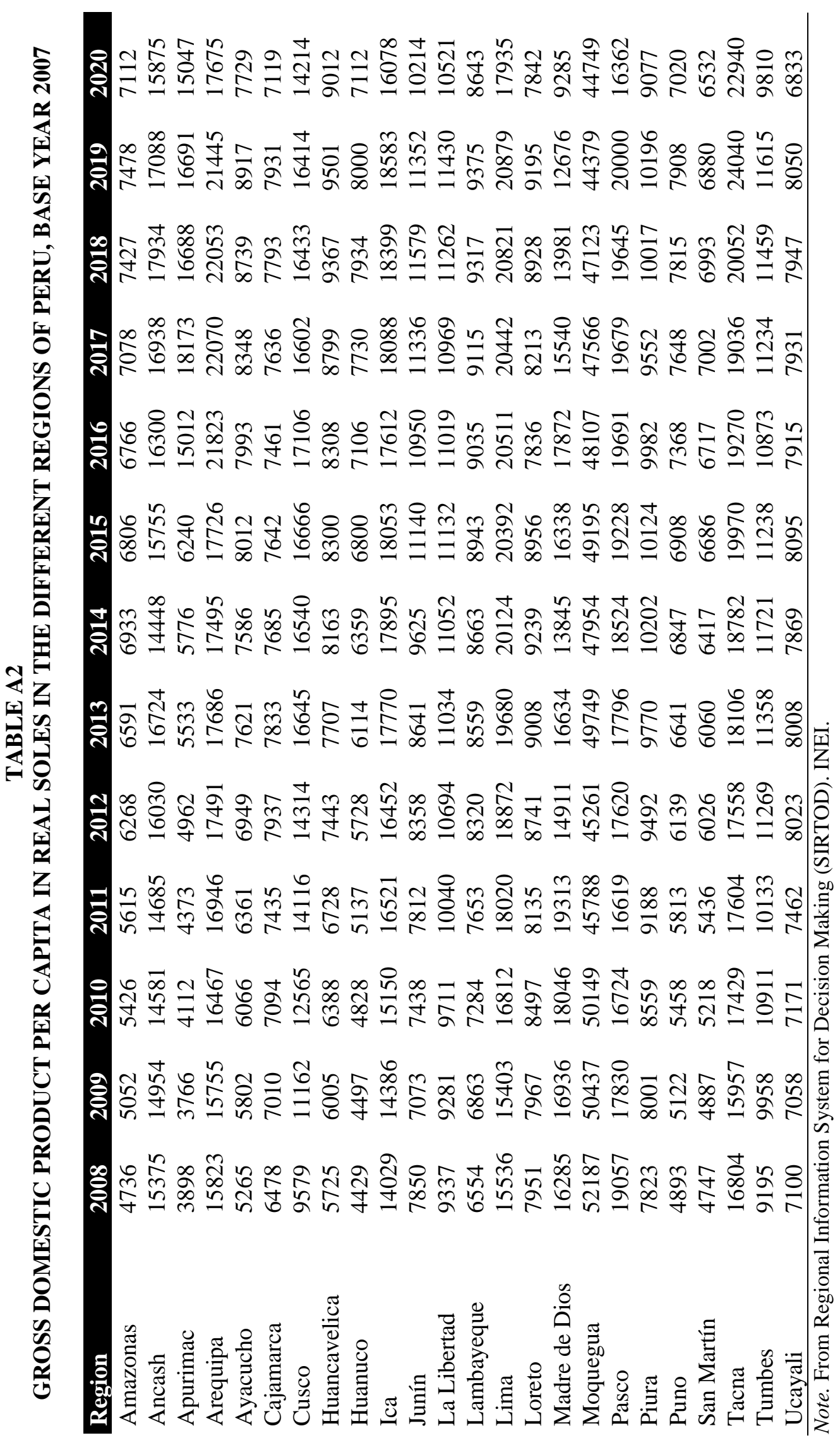




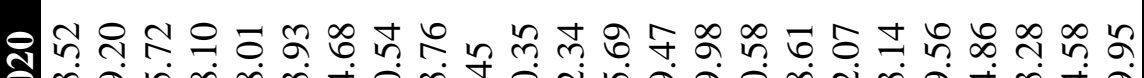

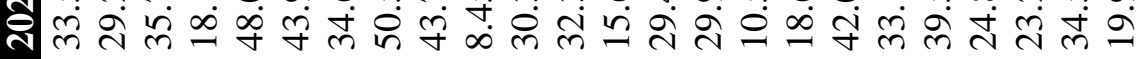

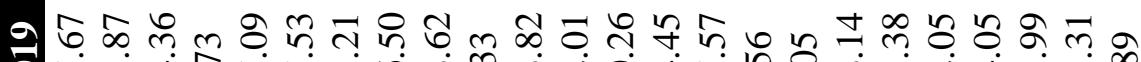

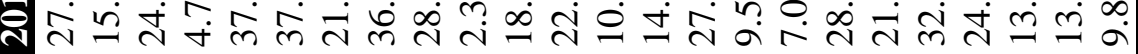

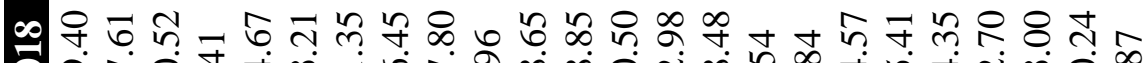
สิते 윰

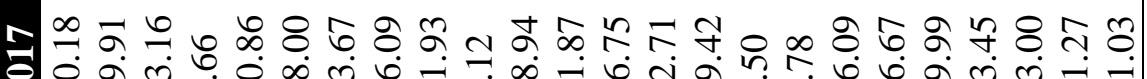
ते

분

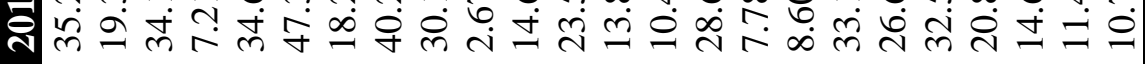

때 궁 สิळ

부ㅇㅠㅛ

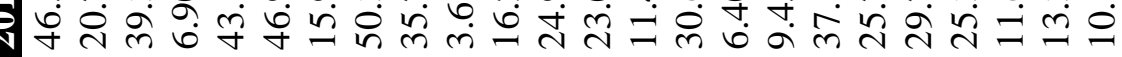

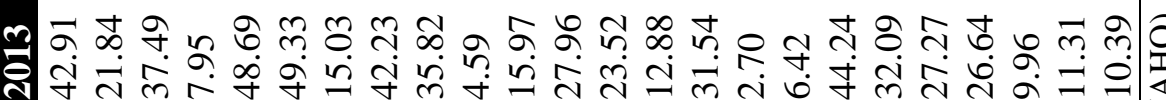

Aิळ

혀

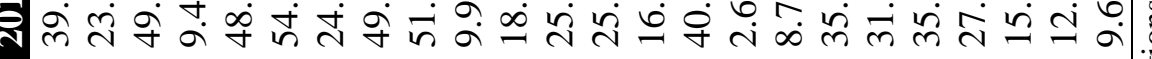

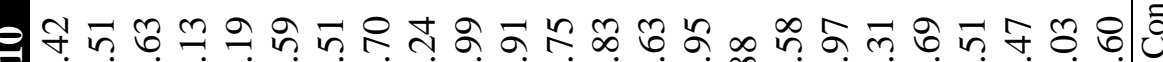

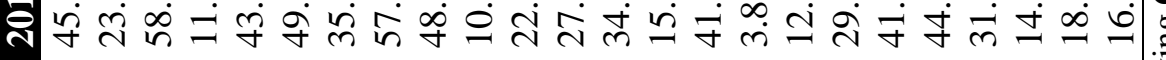

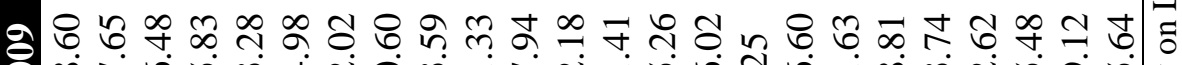

ते

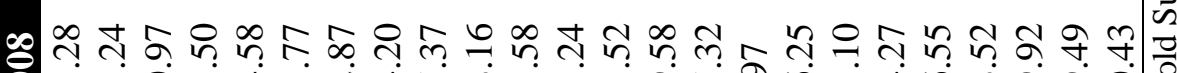

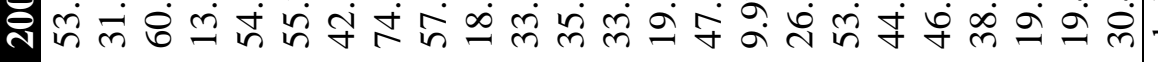

空 
TABLE A4

CORRELATION OF THE VARIABLES

\begin{tabular}{l|lll}
\hline \hline Probability & OBESITY & LN(GDPPC) & POVERTY \\
\hline OBESITY & 1.000000 & & \\
& ---- & & \\
LN(GDPPC) & 0.591908 & 1.000000 & \\
& 0.0000 & ---- & \\
POVERTY & -0.736948 & -0.635695 & 1.000000 \\
& 0.0000 & 0.0000 & ---- \\
\hline \hline
\end{tabular}

$* * * * \mathrm{p}<0.01, * * \mathrm{p}<0.05, * \mathrm{p}<0.10$

34 Journal of Applied Business and Economics Vol. 23(8) 2021 